\title{
Psychological Benefits of Adhering to a Programme of Aerobic Exercise Tony Cassidy*
}

Department of Psychology, University of Ulster, UK

*Corresponding author: Tony Cassidy, Reader, Department of Psychology, University of Ulster, UK, Tel: +(44) 28 70123025; E-mail: t.cassidy@ulster.ac.uk

Received date: March 24, 2016; Accepted date: April 01, 2016; Published date: April 08, 2016

Copyright: ( 2016 Cassidy T. This is an open-access article distributed under the terms of the Creative Commons Attribution License, which permits unrestricted use, distribution, and reproduction in any medium, provided the original author and source are credited.

\begin{abstract}
A matched control design was used to assess adherence to exercise over a 7 week programme and to explore the role of stress, mood, self-efficacy, optimism, resilience, growth and self-compassion in relation to exercise and exercise adherence. Overall 74 female university students, 42 in the experimental condition and 32 in the control group, were assessed at 3 time points over the 7 weeks. Control participants were matched for age and body shape.

Those who scored higher on self-compassion, resilience and growth were more likely to complete the programme and taking part in the programme was associated with increased positive mood and reduced perceived stress. Additionally, exercise appeared to increase optimism, self-efficacy, resilience and perceived growth while reducing pessimism.
\end{abstract}

Keywords: Aerobic exercise; Self-compassion; Resilience; Adherence; Stress

\section{Introduction}

Insufficient physical activity is the 4th leading risk factor for mortality and is linked causally to approximately 3.2 million deaths each year. People who are insufficiently physically active have a $20 \%$ to $30 \%$ increased risk of all-cause mortality compared to those who engage in at least 30 minutes of moderate intensity physical activity most days of the week [1]. The benefits of exercise in terms of health and wellbeing are becoming increasingly well documented [2,3]. Individuals who engage in regular physical activity tend to report significantly higher levels of optimism and self-efficacy and lower levels of pessimism and anxiety. The use of exercise as an intervention to improve the health and wellbeing of individuals with poor physical and/or mental health has been efficacious, for example with hypertension [4], AIDS [5], cancer [6], depression [7], and a range of psychiatric illness [8]. There seems to be well established evidence for the positive health benefits of exercise $[9,10]$.

Despite evidence that participation in 150 minutes of moderate physical activity a week or its equivalent is estimated to reduce the risk of major illness, globally in 2008, 31\% of adults aged $15+$ were insufficiently active (men $28 \%$ and women $34 \%$ ) [1]. Various estimates suggest that 4 out of 5 people who have a gym membership never use it and research suggests that over $50 \%$ of individuals who take part in a fitness program will drop out after the first six months $[11,12]$. This suggests that there exists a large group of people who have some desire and even intention to exercise but who do not follow through.

In addressing the question as to why exercise uptake and adherence is so low it has been suggested that self-esteem plays a central role in the motivation to exercise [13] particularly for women [14] and that participation in exercise increases global self-esteem. In fact, the evidence on self-esteem has led to an emphasis on identifying strategies that increase positive self-esteem as a means of promoting exercise adherence [15]. Organizations such as Esteem through sport and the Canadian Association for the Advancement of Women and Sport and Physical Activity [16] focus on enhancing self-esteem through sport.

One reason suggested as to why this focus has had limited success is that self-esteem is developed through evaluations of self-worth in comparison to others and such comparisons in the exercise arena may lead to negative rather than positive evaluations [17-19]. Selfcompassion [20] has emerged as a positive psychological construct that encourages healthy perspectives of the self and promotes wellbeing that is less contingent on outcomes and performance evaluations and facilitates positive mind states [19]. Self-compassion consists of 3 dimensions (Self kindness, common humanity, mindfulness) which work together as a genuine desire for [18]. It is claimed to be highly stable and easier to enhance than self-esteem as it does not require individuals to adopt unrealistic views of themselves but fosters emotional safety for development and growth [17]. Self-compassion has been seen to facilitate resilience and coping and acts as an emotion regulation strategy that distinguishes negative thought processes and self-evaluations $[18,21,22]$.

Recent research has linked self-compassion with exercise adherence and sport engagement in women [23,24]. Many people exercise in a social context where social evaluations and concerns about body image and athletic performance are common [23]. The promotion of a more self-compassionate outlook may encourage individuals to have increased motivation and enjoyment of exercise, reduce negative selfevaluations and promote a sense of physical self-worth that encourages psychological well-being and maintenance of exercise behavior. Similarly, self-compassion co-exists with less negative evaluations and more positive experience of sport in young female athletes [24].

\section{Aims}

The overall aim of this study was to explore the impact of exercise on psychological health and wellbeing, the relationship between selfcompassion, resilience and personal growth on the impact of exercise, 
Page 2 of 5

and the role of self-compassion in adherence to exercise over a period of 7 weeks.

\section{Method}

\section{Design}

Participants and procedure: A total of 74 female students took part in the study. Of these 42 took part in the exercise programme while 32 age and body shape matched controls were assessed on the same measures but did not take part in the programme. Assessment was carried out before the first exercise session, during the third week of exercising, and during the seventh week for those in the intervention condition. Control group members were assessed during the same weeks and were told they were being assessed to measure mood at different times across the semester.

\section{Measures}

A survey questionnaire was constructed comprising a short demographic section asking about, age, exercise frequency, body shape as well as the following measures.

Perceived stress: The Perceived Stress Scale - 10 item [25] is a 10 item measure of the degree to which one perceives aspects of one's life as uncontrollable, unpredictable, and overloading. It was developed from the Cohen et al. [26] 14 item Perceived Stress Scale (PSS), which was based on Lazarus's theory of stress appraisal. The PSS is designed to measure "the degree to which situations in one's life are appraised as stressful" [26]. Internal consistency of the items was strong ( $\alpha=0.86)$.

Self-efficacy: The Generalized Self-Efficacy Scale (GSES) is a 10 item measure of the self-efficacy concept proposed by Bandura. It reflects an optimistic self-belief in various domains of human functioning. Each item refers to successful coping and implies an internal-stable attribution of success. Cronbach Alpha in this study was 0.85 .

Optimism / Pessimism: The Life Orientation Test-Revised (LOT-R). This consists of 10 items, 3 statements described in a positive manner,
3 statements described in a negative manner, and 4 non-scored items. The 3 positive items were used to measure optimism. Participants responded to the statements by indicating the extent of their agreement along a 5-point Likert scale, ranging from "strongly agree" to "strongly disagree." The internal reliability (Cronbach'a alpha $=0.78$ ) and test-retest reliability $(r=0.68$ over a four-week interval, $r=0.60$ over twelve months, $\mathrm{r}=0.56$ over twenty-four months, and $\mathrm{r}=0.79$ over twenty-eight months) for the unidimensional use of the LOT-R has been shown to be adequate.

Self-compassion: Self-compassion was measured using the Self Compassion Scale [20]. The Self Compassion Scale is a 26-item selfreport inventory and consists of six sub-scales: self-kindness, selfjudgment, awareness of common humanity, isolation, mindfulness, and over-identification. Each item was rated on a 5-point scale $(1=$ strongly disagree to $5=$ strongly agree). Cronbach Alphas were 0.94, $0.94,0.87,0.89,0.92$, and 0.94 for six subscales, respectively.

Resilience: The Brief Resilience Scale (BRS) Smith et al. [27] is a 6 item self- report instrument which measures the ability to bounce back from stress on a Likert scale from $1=$ Strongly Disagree to $5=$ Strongly Agree. The BRS is scored so that a higher score indicates more resilience. It demonstrated good internal consistency $(\alpha=0.91)$.

Personal growth: This was measured using the Personal Growth Initiative Scale [28], which is a 9 item scale designed to measure adversarial growth. In this study it has a Cronbach Alpha of 0.85 .

Mood: This was measured using the Positive and Negative Affect Schedule (PANAS) [29]. This is a 20-item measure of positive and negative affect.

\section{Results}

Means and standards deviations were calculated across the three time points and are shown in Table 1 below.

\begin{tabular}{|c|c|c|c|c|c|c|c|c|}
\hline \multirow[b]{2}{*}{ Variable } & \multicolumn{3}{|c|}{ Control group $(\mathrm{N}=32)$} & \multicolumn{3}{|c|}{ Exercise Group Completers $(\mathrm{N}=\mathbf{2 7}$ ) } & \multicolumn{2}{|c|}{ Non-completers } \\
\hline & T1 & $\mathrm{T} 2$ & T3 & T1 & $\mathrm{T} 2$ & T3 & $\mathrm{T} 1(\mathrm{~N}=25)$ & $\mathrm{T} 2(\mathrm{~N}=11)$ \\
\hline & Mean (Sd) & Mean (Sd) & Mean $(\mathrm{Sd})$ & Mean (Sd) & Mean (Sd) & Mean (Sd) & Mean (Sd) & Mean (Sd) \\
\hline Perceived stress & $3.41(0.87)$ & $3.31(1.12)$ & $3.28(1.14)$ & $3.51(0.80)$ & $2.59(1.22)$ & $1.89(0.85)$ & $3.84(0.75)$ & $3.64(1.03)$ \\
\hline Positive mood & $2.91(1.01)$ & $2.44(1.13)$ & $2.81(1.15)$ & $2.74(0.90)$ & $3.15(0.86)$ & $3.81(0.74)$ & $2.72(0.98)$ & $2.63(0.67)$ \\
\hline Negative mood & $3.00(1.22)$ & $2.81(1.20)$ & $2.88(1.16)$ & $3.26(0.76)$ & $3.30(0.87)$ & $2.19(0.74)$ & $3.28(0.74)$ & $4.18(0.41)$ \\
\hline Self-efficacy & $2.88(0.98)$ & $2.88(0.87)$ & $2.88(1.13)$ & $2.52(0.80)$ & $2.81(0.83)$ & $3.78(0.64)$ & $3.04(0.93)$ & $2.64(1.03)$ \\
\hline Optimism & $2.69(0.82)$ & $2.78(1.01)$ & $2.50(1.05)$ & $2.37(0.79)$ & $2.92(1.01)$ & $3.74(0.66)$ & $2.76(1.20)$ & $2.36(0.92)$ \\
\hline Pessimism & $3.09(1.02)$ & $2.69(1.20)$ & $2.75(1.14)$ & $3.51(0.80)$ & $3.11(1.15)$ & $2.15(0.66)$ & $3.24(1.13)$ & $3.54(0.52)$ \\
\hline Self-kindness & $2.94(0.88)$ & & & $2.63(0.84)$ & & & $1.40(0.50)$ & \\
\hline Self-judgment & $2.72(0.77)$ & & & $2.74(1.06)$ & & & $3.72(1.06)$ & \\
\hline Humanity & $3.53(0.95)$ & & & $3.74(0.81)$ & & & $1.44(0.51)$ & \\
\hline Isolation & $2.93(1.16)$ & & & $2.63(0.88)$ & & & $3.72(0.76)$ & \\
\hline Mindfulness & $3.43(0.88)$ & & & $3.67(0.78)$ & & & $1.64(0.49)$ & \\
\hline
\end{tabular}


Page 3 of 5

\begin{tabular}{|l|l|l|l|l|l|l|l|}
\hline Over identified & $2.91(1.03)$ & & & $2.56(0.85)$ & & $3.76(1.30)$ & \\
\hline Resilience & $2.97(1.09)$ & & $3.11(0.80)$ & & & $1.92(1.01)$ & \\
\hline Personal growth & $2.75(0.72)$ & & & $2.85(0.77)$ & & & $2.24(0.88)$ \\
\hline
\end{tabular}

Table 1: Descriptive statistics for variables by group across time points.

The first stage in analysis was to use one-way analysis of variance (Anova) to test for main effects at Time 1 (T1). The only main effects were for self-kindness $(\mathrm{F}(1,82)=19.37, \mathrm{p}<0.001)$, self-judgement $(\mathrm{F}$ $(1,82)=4.53, \mathrm{p}<0.05)$, common humanity $(\mathrm{F}(1,82)=10.88, \mathrm{p}<$ $0.001)$, and mindfulness $(\mathrm{F}(1,82)=9.12, \mathrm{p}<0.01)$. However, when the sample were split into control group, exercise group completers (i.e. still there at T3), and exercise group non-completers (i.e. dropped out before T3), and analysed using one-way Anova, the effects for control group versus exercise group completers proved not to be significant.
This latter analysis shows main effects for self-kindness (F $(2,81)=\mathrm{v}$ 29.96, $\mathrm{p}<0.001)$, self-judgement $(\mathrm{F}(2,81)=29.96, \mathrm{p}<0.001)$, common humanity $(\mathrm{F}(2,81)=29.96, \mathrm{p}<0.001)$, isolation $(\mathrm{F}(2,81)=$ 29.96, $\mathrm{p}<0.001)$, mindfulness $(\mathrm{F}(1,82)=9.12, \mathrm{p}<0.01)$, overidentified $(\mathrm{F}(2,81)=29.96, \mathrm{p}<0.001)$, resilience $(\mathrm{F}(2,81)=29.96, \mathrm{p}<$ $0.001)$ and personal growth initiative $(\mathrm{F}(2,81)=29.96, \mathrm{p}<0.001)$. Post hoc analysis shows that these main effects were between control group and non-completers and between completers and non-completers (Figure 1).

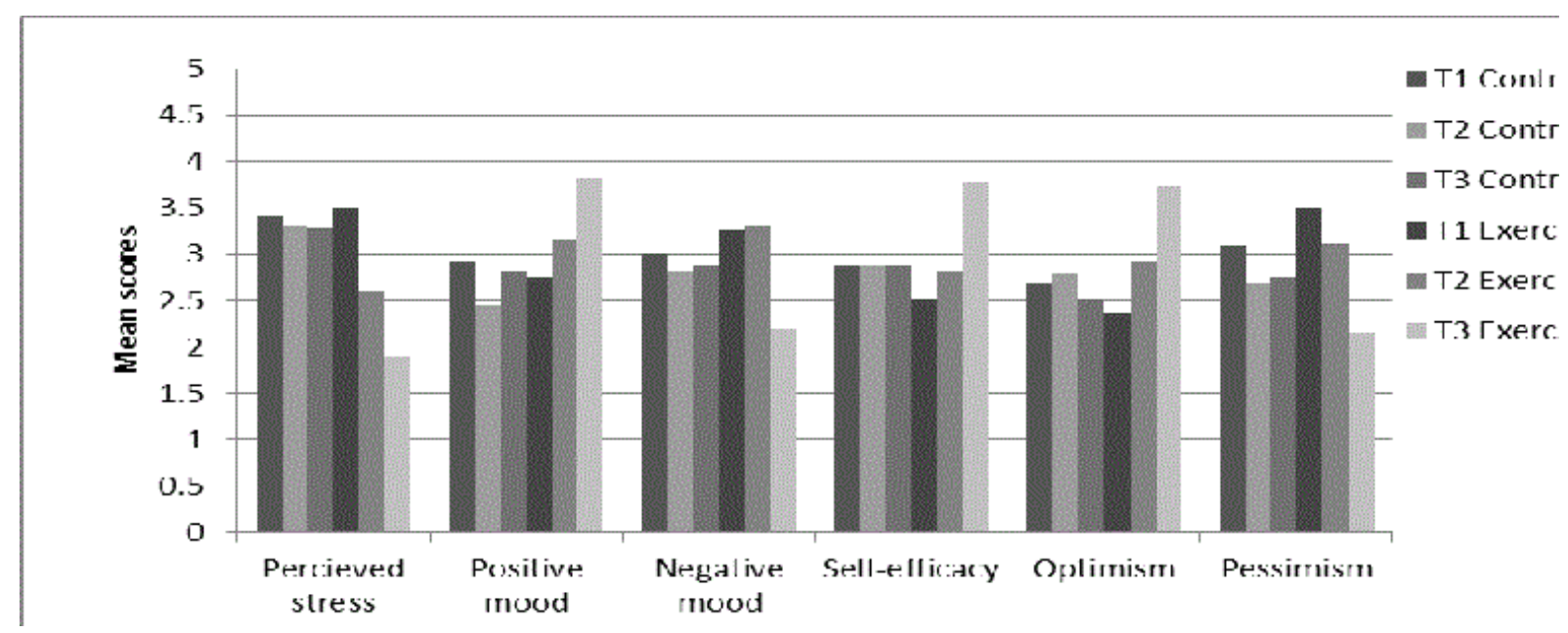

Figure 1: Means scores by group across time.

There was a total of 27 completers, as 25 participants had dropped out before T3 (i.e. non-completers). The non-completers were dropped from the sample for the next analysis. A two by three mixed model analysis of variance with group (exercise completers $N=27$ ) versus control $(\mathrm{N}=32))$ as the between-participants factor and assessment point (T1 by $\mathrm{T} 2$ by $\mathrm{T} 3$ ) as the within-participants factor was used to test for main effects and interactions. This produced the main effects and interactions shown in Table 2.

\begin{tabular}{|l|l|l|l|l|l|l|l|}
\hline Type & \multicolumn{3}{|l|}{ Main effect } & \multicolumn{3}{l|}{ Interaction effect } \\
\hline & df & F & Sig. & & F & Sig. \\
\hline Perceived stress & 1.57 & 56.11 & 0.001 & 0.49 & 41.26 & 0.001 & 0.42 \\
\hline Positive mood & 1.57 & 30.19 & 0.001 & 0.35 & 42.84 & 0.001 & 0.43 \\
\hline Negative mood & 1.57 & 30.49 & 0.001 & 0.34 & 19.11 & 0.001 & 0.25 \\
\hline Self-efficacy & 1.57 & 25.31 & 0.001 & 0.30 & 25.31 & 0.001 & 0.30 \\
\hline Optimism & 1.57 & 21.16 & 0.001 & 0.27 & 36.72 & 0.001 & 0.39 \\
\hline Pessimism & 1.57 & 36.61 & 0.001 & 0.40 & 13.85 & 0.001 & 0.20 \\
\hline
\end{tabular}

Table 2: Main effects and interactions for mixed method anova.

As described above no main effects were observed between groups at T1. However main effects were shown at T2 for perceived stress $(t=$ $3.55, \mathrm{p}<0.001,=0.18)$, and positive $\operatorname{mood}(\mathrm{t}=2.67, \mathrm{p}<0.01,=0.11)$, and at T3 for perceived stress $(\mathrm{t}=5.32, \mathrm{p}<0.001,=0.32)$, positive $\operatorname{mood}(\mathrm{t}=3.91, \mathrm{p}<0.001,=0.21)$, negative $\operatorname{mood}(\mathrm{t}=2.67, \mathrm{p}<0.01$, $=$ 
$0.11)$, self-efficacy $(\mathrm{t}=3.68, \mathrm{p}<0.001,=0.19)$, optimism $(\mathrm{t}=5.33, \mathrm{p}<$ $0.001,=0.33)$, and pessimism $(\mathrm{t}=2.43, \mathrm{p}<0.01,=0.09)$.

\section{Discussion}

The findings first of all show that the exercise and control groups did not differ at baseline on perceived stress, positive and negative mood, optimism or pessimism. Neither did they differ on the dimensions of self-compassion, resilience or personal growth initiative. However, when the exercise group were retrospectively split into those who were still exercising at time 3 (completers) versus those who had dropped out before time 3 (non-completers), non-completers scored significantly lower than either the control group or the completers on self-kindness, common humanity, mindfulness, resilience and personal growth initiative. Non-completers scored significantly higher than either of the other two groups on self-judgement, isolation, and over identification. This supports previous research which shows that positive self-compassion predicts adherence to exercise [23]. The implication of this finding is that individuals who have more selfcompassion (in terms of self-kindness, common humanity, and mindfulness), who are more resilient, and who exhibit a tendency towards growth in the face of adversity, are more likely to stick with it in terms of exercise programmes.

Findings also show positive effects for those who continued to engage in exercise at T3 compared to the control group. These individuals showed significantly reduced perceived stress, negative mood and pessimism, and significantly increased positive mood, selfefficacy, and optimism. The effect sizes for these were generally large as shown by the partial eta squared values. This supports previous research demonstrating the efficacy of exercise interventions. Interestingly the only benefits observed at $\mathrm{T} 2$ were on perceived stress and positive mood and the effect sizes were small to medium. It would appear that for this group real benefits only occurred after engaging in exercise for at least four weeks. The implication of this is that exercise programmes may not show benefits in the short term and measurements of outcome variables may miss beneficial effects if the programme is not given sufficient time to work.

The findings reported have implications for the use of exercise as a therapeutic psychological treatment to improve mental health and also implications for improving adherence to exercise through a focus on self-compassion. Where an exercise programme is part of a behaviour change intervention it may be useful to engage participants in some form of mindfulness or acceptance-commitment intervention in order to increase their self-compassion alongside the exercise regime.

A limitation of this study was the failure to measure motivation and future work could include motives to exercise (intrinsic vs. external) based on self-determination theory which has previously been applied successfully to exercise behaviour. In addition, extending the study to include exercise related outcomes, i.e. goal orientation, social physique anxiety, obligatory exercise behaviour [23] in order to assess and target social comparisons and evaluations of the self from a self-compassion perspective may prove useful.

\section{References}

1. World Health Organisation (WHO) (2014) Prevalence of insufficient physical activity. Global Health Observatory (GHO).

2. Jerstad SJ, Boutelle KN, Ness KK, Stice E (2010) Prospective Reciprocal Relations Between Physical Activity and Depression in Female Adolescents. J Consult Clin Psycho 78: 268-272.
3. Nguyen-Michel ST, Unger JB, Hamilton J, Spruijt-Metz D (2006) Association between physical activity and perceived stress / hassles in college students. Stress and Health 22: 179-188.

4. Maruf FA, Akinpelu AO, Salako BL (2013) Self-Reported Quality of Life Before and After Aerobic Exercise Training in Individuals with Hypertension: A Randomised-Controlled Trial. Appl Psychol Health Well Being 5: 209-224.

5. Dudgeon WD, Phillips KD, Bopp CM, Hand GA (2004) Physiological and Psychological Effects of Exercise Interventions in HIV Disease. Aids Patient Care and Stds 18: 81-98.

6. Courneya KS, Keats MR (2000) Physical exercise and quality of life in cancer patients following high dose chemotherapy and autologous bone marrow transplantation. Psychooncology 9: 127-136.

7. Craft LL, Landers DM (1998) The effects of exercise on clinical depression and depression resulting from mental illness: A meta-analysis. Journal of Sport \& Exercise Psychology 20: 339-357.

8. Penedo FJ, Dahn JR (2005) Exercise and well-being: A review of mental and physical health benefits associated with physical activity. Current Opinion in Psychiatry 18: 189-193.

9. Biddle SJH, Fox KR, Boutcher SH (eds.) (2000) Physical activity and psychological well-being. Routledge, London.

10. Scully D, Kremer J, Graham R, Dudgeon K (1998) Physical exercise and psychological well-being: A critical review. Br J Sports Med 32: 111-120.

11. Berger BG, Pargman D, Weinberg RS (2002) Exercise and enhanced selfconcept and self-esteem. In Berger BG (eds.) Foundations of Exercise Psychology, Morgantown, pp: 53-62.

12. Matsumoto H, Tekenaka K (2004) Motivational profiles and stages of exercise behaviour change. International Journal of Sport and Health Sciences 2: 89-96.

13. McAuley E, Blissmer B, Katula J, Duncan TE, Mihalko SL (2000) Physical activity, self-esteem, and self-efficacy relationships in older adults: A randomized controlled trial. Annals of Behavioral Medicine 22: 131-139.

14. Bowker A, Gadbois S, Cornock B (2003) Sports participation and selfesteem: Variations as a function of gender and gender role orientation. Sex Roles 49: 47-58.

15. Patterson GD (1999) Coaching for the development of self-esteem: The relationship between the self-perceptions of junior cricketers and their perceptions of coaching behavior. Sociology of Sport, 2.

16. Canadian Association for the Advancement of Women and Sport and Physical Activity (2003) Self-esteem, sport, and physical activity.

17. Neff KD, Hsieh Y, Dejitterat K (2005) Self-compassion, achievement goals, and coping with academic failure. Self and Identity 4: 263-287.

18. Neff KD, Kirkpatrick K, Rude SS (2007) Self-compassion and its link to adaptive psychological functioning. Journal of Research in Personality 41: $139-154$

19. Neff KD, Vonk R (2009) Self-compassion versus global self-esteem: Two different ways of relating to oneself. Journal of Personality 77: 23-50.

20. Neff KD (2003) The development and validation of a scale to measure self-compassion. Self and Identity 2: 223-250.

21. Neff KD, McGeehee P (2010) Self-compassion and psychological resilience among adolescents and young adults. Self and Identity 9: 225-240.

22. Neff KD, Rude SS, Kirkpatrick K (2007) An examination of selfcompassion in relation to positive psychological functioning and personality traits. Journal of Research in Personality 41: 908-916.

23. Magnus CMR, Kowalski KC, McHugh TLF (2010) The role of selfcompassion in omen's self-determined motives to exercise and exerciserelated outcomes. Self and Identity 9: 363-382.

24. Mosewich AD, Kowalski KC, Sabiston CM, SedgwickWA, Tracy JL (2011) Self-compassion: A potential resource for young women athletes. J Sport Exerc Psychol 33: 103-123.

25. Cohen S, Williamson G (1988) Perceived stress in a probability sample of the U.S. In Spacapam S, Oskamp S (eds.) The social psychology of health: Claremont Symposium on Applied Social Psychology. Newbury Park, CA, Sage. 
Citation: Cassidy T (2016) Psychological Benefits of Adhering to a Programme of Aerobic Exercise . Clin Exp Psychol 2: 119. doi: 10.4172/2471-2701.1000119

Page 5 of 5

26. Cohen S, Kamarck T, Mermelstein R (1983) A global measure of perceived stress. J Health Soc Behav 24: 385-396.

27. Smith BW, Dalen J, Wiggins K, Tooley E, Christopher P, et al. (2008) The Brief Resilience Scale: Measuring the Ability to Bounce Back. Int J Behav Med 15: 194-200.

28. Robitschek C (1998) Personal Growth Initiative: The construct and its measure. Measurement and Evaluation in Counseling and Development 30: 183-198.
29. Watson D, Clark LA, Tellegen A (1988) Development and validation of brief measures of positive and negative affect: The PANAS scales. J Pers Soc Psycho 54: 1063-1070. 